sehr gute kleine Heft von Leuenberger über die Bienenkrankheiten. Verlag Sauerländer, Arau.

Geinitz.

\section{Vogelschutz und Schädlingsbekümpfung.}

$$
\text { Von }
$$

\section{Dr. H. W. Frickhinger.}

Die Einstellung der beiden Wissenschaften zu diesem Thema ist sehr verschieden. Wenn der Vogelschutz der Ansicht ist, daß es mit den Maßnahmen des Vogelschutzes allein möglich ist, die Kulturpflanzen gegenüber ihren tierischen Feinden genügend zu schützen, so ist das sicherlich ebenso abwegig, als wenn man dem Vogelschutz - mindestens im Obst- uud Gartenbau - jegliche Bedeutung in den Fragen der Schädlingsbekämpfung absprechen wollte.

Da ich selbst seit Jahren - auch im Rahmen der Propagierung der Maßnahmen des Pflanzenschutzes für die Durchführung der Möglichkeiten des Vogelschutzes eintrete und die Belange des Vogelschutzes immer nach Gebühr zu berücksichtigen bestrebt war, halte ich es für meine Pflicht, auch Erfahrungen bekannt zu geben, welche den Bestrebungen des Vogelschutzes nicht unbedingt gemäß sind.

Ich bewohne seit 2 Jahren ein Häuschen, an das sich ein etwa $300 \mathrm{qm}$ umfassender, also kleiner Garten anschließt. Da in dem Gärtchen 3 hohe Bäume stehen, eine Linde, ein Ahorn und eine Birke, habe ich sofort durch Aufhängen einer Berlepsch schen Meisennisthöhle und zweier Starenkobel (Bretternistkästen der bayerischen Vogelwarte Garmisch), sowie einer Halbhöhle (Bretternistgerät) versucht, die Vogelwelt in mein Grundstück anzuziehen. Dieses ist mir heuer anch restlos gelungen, alle Nistgelegenheiten waren besetzt worden, so daß ich auf einem relativ engen Raum 2 Starenpärchen, 1 Kohlmeisenpaar und 1 Haurotschwänzchenpaar zählen konnte. Außerdem brïtet noch auf einem kleinen Holunderbäumchen ein Gartenspötterpärchen. Mein Garten war demnach mit Vögeln sehr gut besetzt und ich war also, vogelschützlerisch gesprochen, für den Pflanzensehutz wohl gerüstet.

Wie überall hatte sich heuer auch in meinem Garten eine starke Blattlausplage eingestellt, an einem Rosenstock sowohl, der sich um den zu ebener Erde gelegenen gedeckten Balkon rankt, wie an meinen Johannisbeersträuchern. Ich habe mich nun oftmals auf die Lauer gelegt und vom ersten Auftreten der Schädlinge an den Vogelbesuch auf den befallenen Pflanzen beobachtet. Das Vogelleben war in diesen Wochen der Hauptbrutpflege wohl sehr rege, ein ständiger An- und Abflug aus allen Nestern war festzustellen. Aber es war sehr selten, daß einmal eine Meise oder ein Rotschwänzchen sich an den Stauden oder an dem Rosengerank zu schaffen machte. Die vielgeschmähten Spatzen konnte ich noch am öftesten dabei beobachten, wie sie am Rosenstock (in der Dachrinne auf dieser Hausseite hatten sie genistet) die Läuse aufpickten. Eine Meise sah ich überhaupt nur einmal sich dieser löblichen Beschäftigung hingeben. Auch das Gartenspötterpärchen huschte gelegentlich durch die Johannisbeersträucher und las Läuse $a b$, aber es schien mir diese Tätigkeit mehr spielerisch zu geschehen, von einer leidenschaftlichen Jagd war hier nichts 210 bemerken. Ich bekam vor der Blattlausinvasion erst Ruhe, als ich mit 1,5 prozent. Venetanlösung den Rosenstock und die Johannisbeerkulturen tüchtig bespritzte, wobei ich allerdings durch eine kleine Verzögerung in der Durchführung viel Arbeit hatte.

Bei der Bekämpfung der Bodenschädlinge mag die Vogelwelt vielleicht eifriger sein, wenigstens lauten verschiedene Beobachtungen hier sehr günstig, die Blattläuse aber scheinen den Vögeln nicht gerade als Leckerbissen zu munden, Aber auch Blattwespenlarven konnten sich in meinem Garten an einem Schneeballenstrauch und an einem Rosenstock in einem Gartenbect stark ausbreiten, ohne daß aber auch hier die Vogelwelt trotz ihrer zahlenmäßigen Stärke erfolgreich eingegriffen hätte.

Meine Erfahrungen mit dem Vogelschutz in meinem kleinen Bereich lauten deshalb nicht allzu ermutigend, wenn ich auch vielleicht, sozusagen zur Entschuldigung dieses Mißerfolges, noch anführen muß, daß in den Nachbargärten nicht der geringste Vogelschutz getrieben wird und die bei mir nistenden Vögel deshalb ein viel weiteres Territorium baben, als ihnen mein kleiner Garten liefern kann. Und dann sei auch nicht vergessen darauf hinzuweisen, daß bei Massenvermehrungen die Vogelwelt in allgemeinen dem Entwicklungstempo der Schädlinge sich niemals noch gewachsen gezeigt hat.

Ich möchte diese ungünstigen Erfahrungen nicht auswerten zu einer Verdammung des Vogelschutzes in unseren Gärten. Auch wenn die Vogelwelt uns nicht die treuen Helfer stellen würde in unserem Kampf gegenüber den Schädlingen, die vielen Freuden, die uns vor unseren Augen brütende Vögel vermitteln, würden es allein schon Iobnen, die Vogelwelt mit allen uns zur Verfügung stehenden Mitteln in unseren Gärten zu hegen.

\section{Milbenkrankheit an Mais.}

Seit 1930 wird in der Forchheimer Gegend (Oberfranken) eine Erkrankung an Mais beobachtet, die einen nur sehr gexingen Kolbenansatz, in schweren Fällen sogar eine vollkommene Unfruchtbarkeit verursacht. Wie K. Flachs in den "Praktischen Blättern für Pflanzenbau und Pflanzensehutz ${ }^{4}$ (1933 Heft 1/2) mitteilt, wurde als Erreger der Krankheit eine Milbe aus der Gattung Pediculopsis festgestellt (wahrscheinlich handelt es sich um die Spezies $P$. graminum E. Rent., die an den verschiedensten Gras- und Getreidearten vorkommt und hier die Ursache für die sogenannte Weißährigkeit darstellt. Von der Lebensweise dieser Milbe ist nach Sorauer bekannt, daß die überwinternden Weibchen, wenn die Wirtspflanzen in die Ähren schießen, in den obersten Blattscheiden auftreten, wo sie das Gewebe zerreißen und es aussaugen. Die angegriffenen Halmteile werden dann mißfarben und schrumpfen, wodurch meist totale Taubährigkeit verursacht wird. Die Milben leben den Sommer über in den Blattscheiden, dort findet auch die Vermebrung und zwar dureh vivipare Weibchen - statt. Auch wenn die Halme im Herbste ganz verwelken, bleiben 